\title{
OBITUARY
}

\section{DOUGLAS JAMES CAMPBELL}

The death of Douglas Campbell, at the age of 56, after a short illness, came as a severe shock to his friends and colleagues in this country and abroad. He was an Edinburgh man who kept his affection for and association with his medical school throughout his professional life, although his main fields of activity were elsewhere. He qualified in 1927, having previously become a licentiate in dental surgery, although he never practised dentistry.

He held the posts of house physician and house surgeon at the Royal Infirmary and then became an assistant in the department of venereal diseases under the distinguished tutelage of the late Dr. David Lees. He took the Diploma of Public Health in 1931 and in 1932 became V.D. Officer and pathologist to the borough of Southampton and Consultant to the Royal Hants and Southampton Hospital. He is still regarded with respect and genuine affection by those who knew him at Southampton. In 1937 he became consultant venereologist to the City of Lincoln and Holland County Council, V.D. Officer and pathologist to Grimsby County Council, and venereologist and dermatologist to the Grimsby Hospital. As an officer in the Territorial Army he was called up in 1939 and served with distinction throughout the war, first as specialist in venereal diseases to the Connaught Hospital and South-Eastern Command; then overseas as adviser in venereology to Allied Forces H.Q. in North Africa, and in Italy; and finally to 21 Army Group of the British Liberation Army. He held the rank of lieutenant-colonel in the Royal Army Medical Corps and was awarded the Territorial Decoration.

He was the first to note and to place on record the emergence of sulphonamide-resistant strains of gonococci which raised considerable difficulties in the control of venereal diseases during the campaign in Italy. In 1945 he returned to his duties at Grimsby, and in 1949 was appointed senior consultant to the V.D. Departments in the Sheffield area, undertaking a task of major reorganization with zeal and ability. In 1950 he was appointed lecturer and clinical teacher in the Sheffield School of Medicine. He established a considerable reputation as clinician, teacher, and administrator. He was past president of the Medical Society for the Study of Venereal Diseases and was for many years an active and most

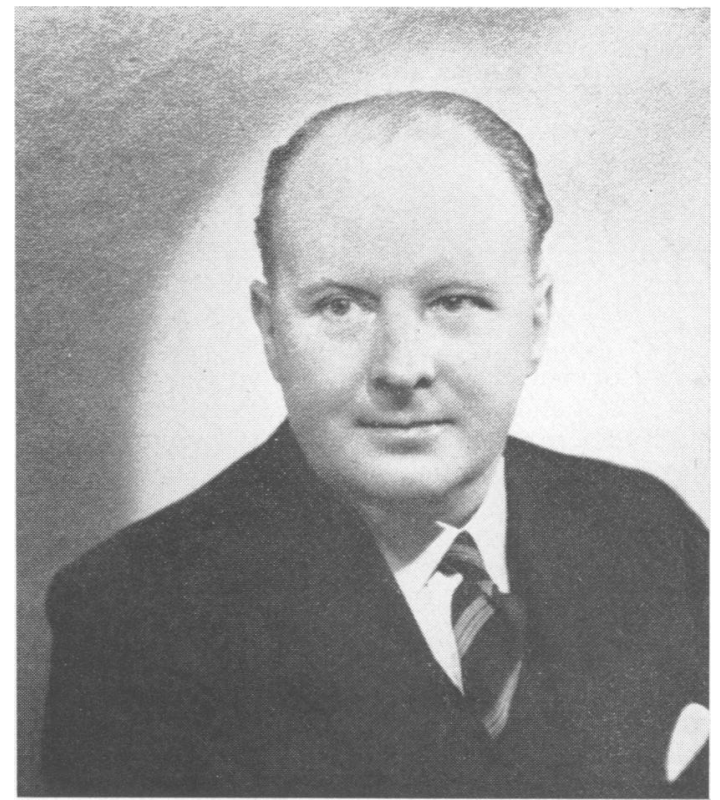

useful member of the Council of that Society. Since 1951 he had been a member of the Editorial Committee of this Journal. He took a leading part in the activities of the Venereologists Group Committee and the Central Consultants and Specialists Committee of the Association. He was devoted to the interests of his special subject and made a considerable contribution to the adjustment and reorganization of the venereal diseases service which became necessary when the National Health Service Act was implemented in 1948 and in the years which followed.

His colleagues knew him as a man of outstanding ability in his own subject, but a certain reserve obscured some other facets of his many-sided character, except to those who knew him best. He was a deeply religious man whose life was guided and directed by his faith and this was probably responsible for the sense of dedication which he brought to work. He was devoted to his family. He will be sorely missed not only by his immediate colleagues in the Sheffield Region, but by those engaged in venereology throughout the country. He leaves a widow and two sons to whom the thoughts of all his friends will turn in their sorrow. A.J.K. 